\title{
Effects of low-fat compared with high-fat diet on cardiometabolic indicators in people with overweight and obesity without overt metabolic disturbance: a systematic review and meta-analysis of randomised controlled trials
}

\author{
Mengqing $\mathrm{Lu}^{1} \dagger$, Yi Wan ${ }^{1} \dagger$, Bo Yang ${ }^{1,2}$, Catherine E. Huggins ${ }^{3}$ and Duo $\mathrm{Li}^{1,3,4 *}$ \\ ${ }^{1}$ Department of Food Science and Nutrition, Zhejiang University, Hangzhou, 310058, People's Republic of China \\ ${ }^{2}$ School of Public Health and Management, Wenzhou Medical University, Wenzhou, People's Republic of China \\ ${ }^{3}$ Department of Nutrition, Dietetics and Food, Monash University, Melbourne, VIC 3800, Australia \\ ${ }^{4}$ Institute of Nutrition and Health, Qingdao University, Qingdao, People's Republic of China \\ (Submitted 26 May 2017 - Final revision received 23 September 2017 - Accepted 26 September 2017- First published online 7 December 2017)
}

\begin{abstract}
Randomised controlled trials comparing low- $v$. high-fat diets on cardiometabolic risk factors in people with overweight or obesity have shown inconsistent results, which may be due to the mixed metabolic status of people with excess adiposity. The role of dietary fat manipulation in modifying cardiometabolic indicators in people with overweight or obese without metabolic disturbance is unclear. Thus, meta-analysis was conducted to compare low- $v$. high-fat diets on cardiometabolic indicators in people who are overweight or obese without metabolic disturbance in the present study. Databases were searched until October 2016. The pooled effects of outcomes with heterogeneity were calculated with a random-effects model, heterogeneities were analysed by subgroup and meta-regression. As a result, twenty studies with 2106 participants were included in the meta-analysis. Total cholesterol and LDL-cholesterol levels were lower following low-fat diets compared with high-fat diets: weighted mean difference (WMD) was $-7 \cdot 05 \mathrm{mg} / \mathrm{dl}(-0 \cdot 18 \mathrm{mmol} / 1 ; 95 \% \mathrm{CI}-11 \cdot 30,-2 \cdot 80 ; P=0 \cdot 001)$ and $-4.41 \mathrm{mg} / \mathrm{dl}(-0.11 \mathrm{mmol} / \mathrm{l} ; 95 \% \mathrm{CI}-7.81,-1 \cdot 00 ; P=0.011)$, respectively. Conversely, significant higher level of TAG (WMD: $11.68 \mathrm{mg} / \mathrm{dl}$ $(0.13 \mathrm{mmol} / \mathrm{l}), 95 \% \mathrm{CI} 5.90,17.45 ; P<0.001)$ and lower level of HDL-cholesterol (WMD: $-2.57 \mathrm{mg} / \mathrm{dl}(-0.07 \mathrm{mmol} / \mathrm{l}) ; 95 \% \mathrm{CI}-3.85,-1 \cdot 28$; $P<0.001)$ were found following low-fat diets compared with high-fat diets. In conclusion, dietary fat manipulation has a significant influence on blood lipid levels in people with overweight or obesity without metabolic disturbances.
\end{abstract}

Key words: Low-fat diets: High-fat diets: Metabolically healthy obese: Blood lipids

Excessive body weight (BW) is a global public health issue. According to the WHO's investigation in 2015, worldwide obesity has more than doubled since $1980^{(1)}$. Excess adiposity is associated with chronic diseases through various metabolic pathways and their complications such as elevated blood pressure, elevated plasma glucose and dyslipidaemia ${ }^{(2-4)}$. Traditional weight loss diets are usually low in fat to decrease overall daily energy intake and because of the favourable effects on blood lipids ${ }^{(5)}$. This traditional dogma is now contentious with several studies comparing low-fat with high-fat diet showing variable results on BW and cardiometabolic indicators in people with overweight or obesity ${ }^{(6-9)}$. Notably two systematic reviews and meta-analyses ${ }^{(8,9)}$ have reported common findings that high-fat diets $v$. low-fat diets result in higher fasting plasma total cholesterol (TC) and LDL-cholesterol, but lower fasting plasma TAG and higher HDL-cholesterol. The effects on BW are less clear with one meta-analysis reporting that overall there is no difference when comparing low-fat $v$. high-fat diets, however when these diets were combined with energy restriction the difference was greater with the high-fat intervention $^{(9)}$. Whereas in a more recent meta-analysis there was a greater change in BW after high-fat diets compared with low-fat diets ${ }^{(8)}$. As there appears to be elevated LDL-cholesterol with consumption of high-fat diets, caution has ensued in recommending this dietary pattern in combination with overall energy restriction for facilitating weight loss.

Dietary fat may confer different effects on blood lipids in people with overweight or obesity depending on whether there is underlying metabolic disease or not. Excess adiposity is not always concomitant with metabolic complications or CVD. These people have been described as 'metabolically healthy obese' $(\mathrm{MHO})^{(10-12)}$. MHO individuals are characterised by

Abbreviations: BW, body weight; DBP, diastolic blood pressure; Hs-CRP, high-sensitivity C creative protein; MHO, metabolically healthy obese; MUO, metabolically unhealthy obese; RCT, randomised controlled trial; SBP, systolic blood pressure; TC, total cholesterol; WMD, weighted mean difference.

* Corresponding author: Professor D. Li, fax +86 571 88982024, email duoli@zju.edu.cn

$\dagger$ These authors have the same contribution to the article. 
reduced cardiometabolic risk (relative to weight-matched individuals with metabolic disturbances), as reflected by preserved insulin sensitivity, a reduced inflammatory status and a normal circulating lipid profile ${ }^{(13)}$. Importantly, recent studies estimate that the prevalence of this phenotype may be as high as $30 \%$ of the obese population $^{(14,15)}$. If excess adiposity is sustained a metabolically unhealthy phenotype may develop ${ }^{(16)}$. This is an important sub-clinical population to study to assist with development of strategies which aim to prevent the onset of metabolic complications. A growing number of studies show that in addition to lifestyle and dietary differences, there are also differences in the expression of genes linked to CVD progression in this sub-clinical population, compared with those who have excess adiposity in combination with metabolic disturbances ${ }^{(17-20)}$. With the increased number of randomised controlled trials (RCT) that have compared a low-fat diet with a high-fat diet in metabolically healthy people with overweight or obesity, a systematic review and meta-analysis to summarise the impact of these diets on cardiometabolic risk factors is now warranted. This is important for developing best-practice dietary guidelines, particularly for $\mathrm{MHO}$ populations.

\section{Methods}

\section{Literature search}

All of the processes of article searching were conducted by two investigators independently. Literature search was limited to RCT without any restriction on language or calendar date. The databases MEDLINE, EMBASE and the Cochrane Trial Register were searched through to October 2016. The structured search strategies used the following format of terms: (low fat diet OR low fat diets OR reduced fat) AND (obese OR obesity OR overweight OR weight loss). This combination of search terms were selected to ensure that all relevant studies were identified through and screened for eligibility. The reference lists of retrieved articles were also checked for additional publications. This systematic review was conducted in adherence to the standards of the Preferred Reporting Items for Systematic Review and Meta-Analysis statement ${ }^{(21)}$.

\section{Eligibility criteria}

Studies were reviewed by title and abstract first and then the fulltext for the final eligibility of a study. Only studies that met all of the following criterions were included: (i) RCT; (ii) the BMI of the participants $\geq 25 \mathrm{~kg} / \mathrm{m}^{2}$; (iii) the intervention should be a low-fat diet ( $<30 \%$ of total energy consumption) compared with a highfat diet ( $\geq 30 \%$ of total energy consumption); (iv) participants are metabolically healthy according to Wildman et $a l^{(22)}$ : where less than two of the following criterions should be found: blood pressure $\geq 130 / 85 \mathrm{mmHg} ; \quad$ TAG $\geq 1.7 \mathrm{mmol} / \mathrm{l} ; \quad$ HDL-cholesterol for men $<1.03 \mathrm{mmol} / 1$, for women $<1.30 \mathrm{mmol} / \mathrm{l}$; glucose $\geq 5.6$ $\mathrm{mmol} / \mathrm{l}$; homoeostasis model assessment-insulin resistance $>4 \cdot 27$ (i.e. 90th percentile); high-sensitivity C-reactive protein (Hs$\mathrm{CRP}$ ) $>7.89 \mathrm{mg} / \mathrm{dl}$ (i.e. 90th percentile); (v) having at least one of the outcomes (BW, systolic blood pressure (SBP), diastolic blood pressure (DBP), LDL-cholesterol, HDL-cholesterol, TC, TAG, insulin, glucose, leptin, total adiponectin and Hs-CRP) for assessment and report of post intervention mean or mean of two time point values with standard deviation (or basic data to calculate these parameters).

Studies were excluded if the high-fat diet accounted for only $30 \%$ of the total energy or if any of the participants were using drugs that could influence the result of interest (lipid modification drugs, hormone drugs, slimming drugs, etc.). Diets that replaced fat with artificial fat were excluded. If there were studies published as updates, only the study that had the most outcomes of interest was included.

\section{Data extraction}

For all included studies, the following data were extracted: the first author's name, date of publication, country where participants reside, follow-up period, study design, drop-out rate, total number of participants, female percentage and post intervention mean values or differences in mean of two time point values with corresponding standard deviation. In case of more than one low-fat group or high-fat group within a single study design, data were combined according to the methods recommended by the Cochrane collaboration ${ }^{(23)}$. If standard deviation was not provided, it was calculated from standard error of mean or $95 \%$ CI. Extracted data were turned to unified units. For TC, LDL-cholesterol and HDL-cholesterol, $1 \mathrm{mmol} / 1$ was converted to $38.61 \mathrm{mg} / \mathrm{dl}$; for TAG, $1 \mathrm{mmol} / \mathrm{l}$ was converted to $88.50 \mathrm{mg} /$ $\mathrm{dl}$; for plasma glucose, $1 \mathrm{mmol} / \mathrm{l}$ was converted to $18 \mathrm{mg} / \mathrm{dl}$.

\section{Quality assessment and risk of bias}

Methodology quality of the included studies were assessed by both the JADAD score and risk of bias assessment. Two investigators conducted the assessment independently. The modified JADAD score (seven-point) was used according to randomisation (randomisation $=1$ point, random number generated by computer or similar methods $=$ an additional 1 point), concealment of allocation (random number table or similar methods $=1$ point, the allocation scheme is controlled by centre or pharmacy, or using of opaque envelopes or other methods that be secret to clinicians and subjects of the allocation methods = an additional 1 point), double-blinding (double-blind $=1$ point, use of a placebo $=$ additional 1 point), withdrawals and dropouts (numbers and reasons for drop-out are stated $=1$ point). Final scores of $0-3$ points were considered to be of low quality and 4-7 points as high quality ${ }^{(4,24)}$.

Risk of bias of the included studies were assessed using the Cochrane Collaboration's risk of bias tool following six domains: (i) selection bias (random sequence generation allocation concealment); (ii) performance bias (blinding of participants and personnel); (iii) detection bias (blinding of outcome assessment); (iv) attrition bias (incomplete outcome date); (v) reporting bias (selective reporting); (vi) other bias ${ }^{(25)}$. Data were analysed using Review Manager 5.3 software to give an overview of the risk of bias within the included studies against theses six domains.

\section{Statistical analysis}

Meta-analysis was performed for all outcomes to determine the pooled effect of the intervention. A random-effects model described by DerSimonian \& Laird $^{(26)}$ was used to estimate 
weighted mean differences (WMD) with $95 \%$ CI. Heterogeneity of the trial results were tested by $Q$ test and $I^{2}$ parameter. $I^{2} \leq 25 \%$ was considered to be low heterogeneity, $25 \%<I^{2} \leq 50 \%$ moderate heterogeneity, whereas $I^{2} \geq 75 \%$ was considered to be high heterogeneity ${ }^{(27)}$. In order to find out the source of heterogeneity, subgroup analysis was carried out for outcomes that had a moderate or high heterogeneity focused on the following covariates : the percentage of female ( $>80$ or $\leq 80 \%$ ); fat percentage of high-fat diet ( $\geq 45$ or $<45 \%$ ); carbohydrate percentage of lowfat diet ( $>55$ or $\leq 55 \%$ ); duration $(<3,3-6$ or $>6$ months); energy restriction (both restricted or low fat only or high fat only or no); high-fat diet type (low-carbohydrate diet or other high-fat diet types); drop-out rate (>20 or $\leq 20 \%$ ); Continent (North America, Europe or others); the JADAD score $(\geq 4$ or $<4)$. Univariate metaregression was also conducted where there were more than 10 studies including the dependent variables of interest. Most of the cut points of subgroups were chosen by median. Sensitivity analysis was applied to assess whether one single study influenced the results excessively. Begg's test and Egger's test were performed and the symmetry of the funnel plots assessed to examine potential publication bias. All of the analyses were conducted using Stata/SE 12.0 (add publisher/manufacture details). Twosided $P<0.05$ was considered to be statistically significant

\section{Results}

\section{Literature search}

A total of 4877 articles were retrieved: 989 from Medline, 2324 from Embase and 1564 from the Cochrane trial register. Following first and second pass screening, twenty studies were eligible for inclusion, resulting in 2106 participants for the metaanalysis ${ }^{(28-47)}$. Details for the screening steps and reasons for exclusion are shown in Fig. 1.

\section{Characteristics of studies included}

Included studies were published between 1993 and 2014 and intervention duration ranged from 6 weeks to 2 years. Most of the trials were conducted in USA ( $n$ 12). All participants were adults aged $\geq 18$ years old and $\mathrm{BMI} \geq 25 \mathrm{~kg} / \mathrm{m}^{2}$. Five of the studies were conducted exclusively on women. The proportion of energy from fat in low-fat diet ranged from 12 to $30 \%$, whereas carbohydrate ranged from 52 to $65 \%$. There were twelve trials with restricted energy intake in both diets. The number of included studies reporting on outcomes of interest were as follows: BW ( $n$ 14), SBP and DBP ( $n$ 10), plasma LDLcholesterol ( $n$ 18), HDL-cholesterol ( $n$ 18), TC ( $n$ 16), TAG ( $n$ 19), plasma insulin ( $n$ 14), plasma glucose ( $n$ 14), leptin ( $n$ 5), adiponectin ( $n$ 3) and Hs-CRP ( $n$ 7) respectively. Nine of the included studies scored $\geq 4$ of the JADAD score, no study scored less than 2 points (Table 1 ). No obviously high risk of bias was found (Fig. 2).

\section{The effects of low-fat diet compared with high-fat diet on cardiometabolic indicators}

A more pronounced reduction of TC and LDL-cholesterol was found after following a low-fat diet compared with high-fat diets: WMD $-7.05 \mathrm{mg} / \mathrm{dl}(-0.18 \mathrm{mmol} / 1 ; 95 \% \mathrm{CI} 11 \cdot 30,-2 \cdot 80$; $P=0.001)$ and $-4.41 \mathrm{mg} / \mathrm{dl}(-0.11 \mathrm{mmol} / 1 ; 95 \% \mathrm{CI}-7 \cdot 81,-1 \cdot 00$; $P=0.011$ ), respectively. Conversely, HDL-cholesterol was lower and TAG higher after the low-fat diet compared with high-fat diets: WMD were $-2.57 \mathrm{mg} / \mathrm{dl}(-0.07 \mathrm{mmol} / \mathrm{l} ; 95 \%$ CI 3.85 , $-1.28 ; P<0.001)$ and $11.68 \mathrm{mg} / \mathrm{dl}(0.13 \mathrm{mmol} / \mathrm{l} ; 95 \%$ CI 5.90 , 17.45; $P<0.001)$, respectively. Low-fat diet was also associated with higher DBP compared with high-fat diets, the WMD was $2.18 \mathrm{~mm} \mathrm{Hg}$ (95\% CI 0.74, 3.62; P=0.003). There appeared to be no significant difference between low-fat and high-fat diets on: BW $(P=0.548)$, SBP $(P=0.114)$, plasma glucose $(P=0.347)$, plasma insulin $(P=0.106)$, leptin $(P=0.679)$, Hs-CRP $(P=0 \cdot 623)$ or adiponectin $(P=0 \cdot 100)$ (Table 2$)$ (Fig. 3).

\section{Subgroup and meta-regression analysis}

Low heterogeneity between studies was detected for TAG $\left(I^{2}=10 \cdot 8 \%\right)$, SBP $\left(I^{2}=0 \%\right)$ and DBP $\left(I^{2}=0 \%\right)$. Moderate heterogeneity were found in TC $\left(I^{2}=32 \cdot 8 \%\right)$, plasma insulin $\left(I^{2}=42 \cdot 9 \%\right)$, plasma glucose $\left(I^{2}=25 \cdot 8 \%\right)$, leptin $\left(I^{2}=25 \cdot 1 \%\right)$, Hs-CRP $\left(I^{2}=29 \cdot 6 \%\right)$ and adiponectin $\left(I^{2}=49 \cdot 3 \%\right)$. High heterogeneity were found in LDL-cholesterol $\left(I^{2}=56.7 \%\right)$, HDLcholesterol $\left(I^{2}=69 \cdot 4 \%\right)$ and BW $\left(I^{2}=72 \cdot 7 \%\right)$.

For the studies that measured TC, TAG, HDL-cholesterol, LDL-cholesterol, subgroup analyses found that the following factors confounded the effects of low-fat diet compared with high-fat diet: drop-out rate $>20 \%$ and the JADAD score $<4$, $P$ values of these four indicators remained significant only when drop-out rate $<20 \%$ and the JADAD score $>4$. The proportion of dietary fat on the high-fat diet was also a source of heterogeneity and for studies where dietary fat $\geq 45 \%$, there was a greater change for the size effects of TAG (WMD: $35.26 \mathrm{mg} / \mathrm{dl} ; 95 \%$ CI 20.15, 50.36; $P<0.001)$ and BW (WMD: $3.98 \mathrm{~kg} ; 95 \%$ CI $2 \cdot 25,5.72 ; P<0.001)$ on the low-fat diet compared with high-fat diet. Compared with high-fat diet, the reduction of LDL-cholesterol was more marked when carbohydrate percentage $\leq 55 \%$ in low-fat diet (WMD: $-6.87 \mathrm{mg} / \mathrm{dl}$; $95 \%$ CI $-11 \cdot 20,-2 \cdot 54 ; P=0.002)$. When female percentage $\leq$ $80 \%$, fasting plasma glucose was greater after low-fat diet compared with high-fat diet $(P=0.002)$. However, most of the heterogeneity were only partly explained by subgroups (Tables 3 and 4).

\section{Sensitivity analysis and publication bias}

Sensitivity analysis showed there was no apparent difference for the pooled estimate of the WMD for the effects of low-fat diet on BW, HDL-cholesterol, TC, TAG, SBP, DBP, or LDLcholesterol after any one study was removed (online Supplementary Fig. S1-S12). The results for Begg's rank correlation test and Egger's linear regression test indicated that there were no obvious publishing bias detected in the metaanalysis of BW, TC, TAG, SBP, DBP, LDL-cholesterol, plasma insulin, leptin, Hs-CRP and adiponectin. Publication bias may exist for HDL-cholesterol and plasma glucose according to Egger's linear regression test $(P<0.001)$, however, it was not evident from the Begg's rank correlation test $(P=0 \cdot 820$, $P=0.477$ ) (Table 5 and online Supplementary Fig. S13-S36). 


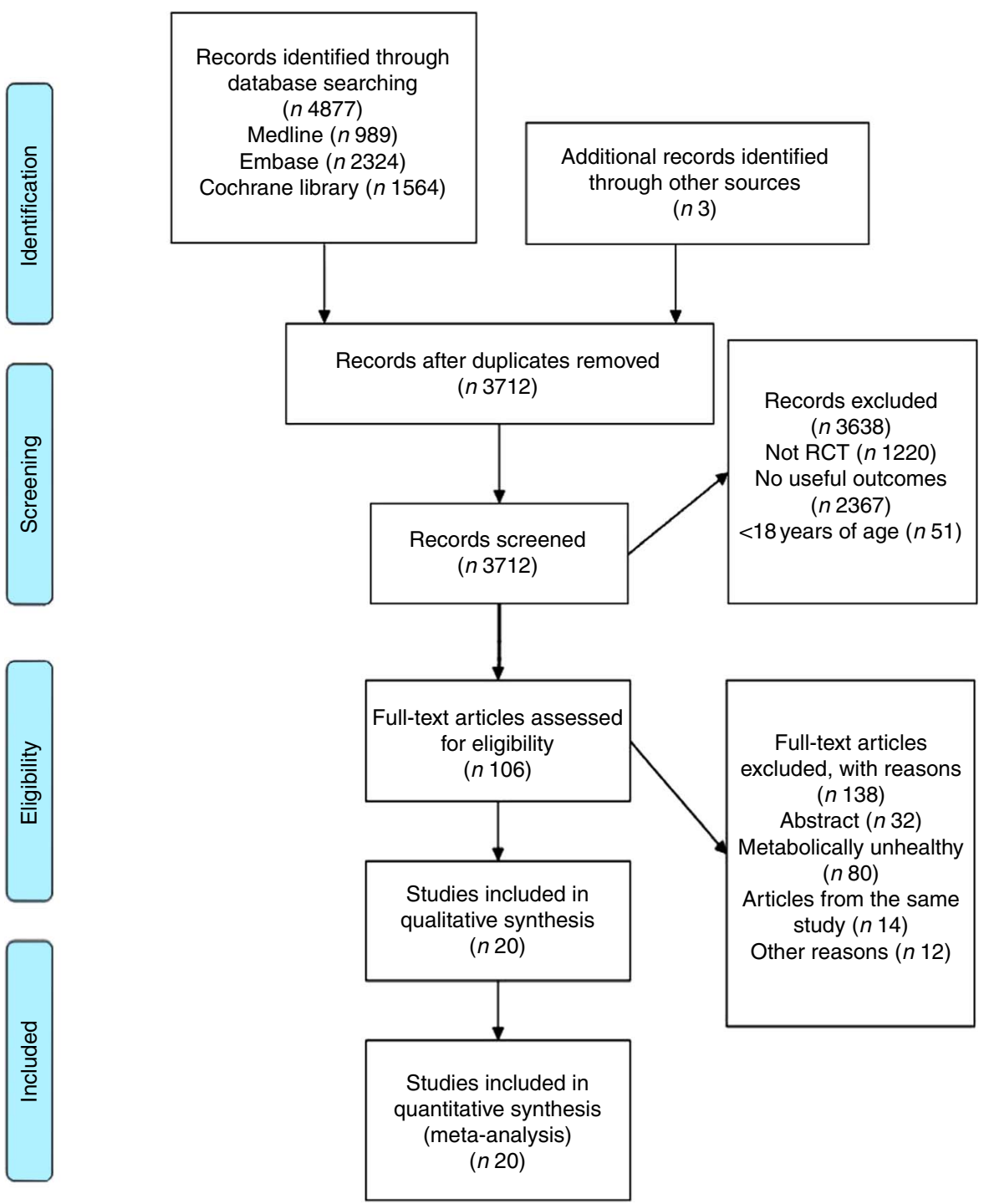

Fig. 1. Flow chart for article selection process. RCT, randomised controlled trial.

After further analysed by the trim and fill method, there were no articles indicated to be trimmed, which suggests little evidence for publication bias.

\section{Discussion}

To our knowledge, this is the first meta-analysis to systematically compare the effects of low-fat diet with high-fat diet in people who are metabolically healthy but are overweight or obese. This is important for contributing to understanding what factors may be involved in the transition from a metabolically healthy profile to a metabolically unhealthy profile and consequently increase disease risk. Findings of this metaanalysis suggests that short- to medium-term ( 6 months- 2 years) intake of low dietary fat compared with high dietary fat was associated with lower plasma TC and LDL-cholesterol. Conversely, low-fat diet was associated with a more unfavourable change in TAG, HDL-cholesterol and DBP compared with high-fat diet. There appeared to be little impact of the low-fat diet on other cardiometabolic risk factors compared with highfat diet including BW, SBP, plasma insulin, plasma glucose, leptin, adiponectin and Hs-CRP. These results should be explained cautiously.

\section{Metabolic phenotype with excess adiposity}

The results of this meta-analysis are consistent with that of Schwingshackl \& Hoffmann's ${ }^{(9)}$, who compared low-fat diets with high-fat diets in overweight and obese populations without screening of metabolic status, and the results found low-fat diets were associated with lower TC and LDL-cholesterol levels, whereas high-fat diets were associated with lower TAG level and higher HDL-cholesterol level. However, WMD of all of the four blood lipid indicators were more remarkable in the present meta-analysis than Schwingshackl \& Hoffmann's ${ }^{(9)}$, which suggests that overweight and obese populations with healthy metabolism have a more distinct reaction to dietary fat than those metabolically unhealthy people. 
Table 1. Characteristics of randomised controlled trials included (Percentages and numbers)

\begin{tabular}{|c|c|c|c|c|c|c|c|c|}
\hline Author, year & Country & $\begin{array}{c}\text { Female } \\
(\%)\end{array}$ & $\begin{array}{l}\text { Participant* } \\
\text { (n) }\end{array}$ & $\begin{array}{l}\text { Duration } \\
\text { (Weeks) }\end{array}$ & Low-fat diet intervention & High-fat diet ntervention & Drop-out (\%) & $\begin{array}{l}\text { JADAD† } \\
\text { score }\end{array}$ \\
\hline Brehm et al., 2003 & USA & 100 & 53 & 24 & $\begin{array}{c}\text { Energy restricted } \\
30 \% \text { fat, } 55 \% \\
\text { carbohydrate }\end{array}$ & $\begin{array}{l}\text { Atkins } \ddagger \\
\quad \text { low-carbohydrate diet }\end{array}$ & $20 \cdot 8$ & 4 \\
\hline \multicolumn{9}{|l|}{ Brehm et al., 2005} \\
\hline & USA & 100 & 50 & 16 & $\begin{array}{c}\text { Energy restricted } \\
30 \% \text { fat, } 55 \% \\
\text { carbohydrate }\end{array}$ & $\begin{array}{l}\text { Atkins } \\
\text { low-carbohydrate diet }\end{array}$ & $20 \cdot 0$ & 4 \\
\hline Pelkman et al., 2004 & USA & 69 & 53 & 6 & $\begin{array}{l}\text { Energy restricted } \\
20 \% \text { fat }\end{array}$ & $\begin{array}{l}\text { Energy restricted } \\
35 \% \text { fat }\end{array}$ & 1.9 & 2 \\
\hline Ebbeling et al., 2007 & USA & 79 & 73 & 72 & $\begin{array}{l}\text { Energy restricted } \\
20 \% \text { fat } \\
55 \% \text { carbohydrate }\end{array}$ & $\begin{array}{l}\text { Energy restricted } \\
\text { Low-glycaemic load } \\
\text { diet (35\% fat, } 40 \% \\
\text { carbohydrate) }\end{array}$ & $30 \cdot 1$ & 5 \\
\hline Bladbjerg et al., 2011 & Denmark & 58 & 131 & 24 & $\begin{array}{l}20-30 \% \text { fat } \\
55-65 \% \text { carbohydrate }\end{array}$ & $\begin{array}{l}\text { MUFA diet (35-45\% fat, } \\
\text { 40-50\% } \\
\text { carbohydrate); } \\
\text { Danish§ diet (30-40\% } \\
\text { fat, } 45-55 \% \\
\text { carbohydrate) }\end{array}$ & 24.4 & 2 \\
\hline Foster et al., 2010 & USA & 68 & 307 & 96 & $\begin{array}{c}\text { Energy restricted } \\
30 \% \text { fat, } 55 \% \\
\text { carbohydrate }\end{array}$ & $\begin{array}{l}\text { Atkins } \\
\text { low-carbohydrate diet }\end{array}$ & 0.0 & 4 \\
\hline Lovejoy et al., 2003 & USA & 0 & 45 & 36 & $\begin{array}{l}\text { Energy restricted } \\
25 \% \text { fat } \\
58 \% \text { carbohydrate }\end{array}$ & $\begin{array}{l}\text { Energy restricted } \\
33 \% \text { fat } \\
52 \% \text { carbohydrate }\end{array}$ & $18 \cdot 9$ & 4 \\
\hline Kasim et al., 1993 & USA & 100 & 72 & 48 & $\begin{array}{l}\text { Energy restricted } \\
15 \% \text { fat }\end{array}$ & Usual diet & $0 \cdot 0$ & 2 \\
\hline Kelly et al., 2003 & Canada & 75 & 40 & 10 & Energy restricted $18 \%$ fat & $\begin{array}{l}\text { Energy restricted } \\
55 \% \text { fat }\end{array}$ & $22 \cdot 5$ & 2 \\
\hline Petersen et al., 2006 & Denmark & 75 & 771 & 10 & $\begin{array}{l}\text { Energy restricted } \\
20-25 \% \text { fat, } 60-65 \% \\
\text { carbohydrate }\end{array}$ & $\begin{array}{l}\text { Energy restricted } \\
\quad 40-45 \% \text { fat } \\
40-45 \% \text { carbohydrate }\end{array}$ & $17 \cdot 1$ & 5 \\
\hline Cornier et al., 2005 & Sweden & 100 & 12 & 16 & $\begin{array}{l}\text { Energy restricted } \\
20 \% \text { fat, } \\
60 \% \text { carbohydrate }\end{array}$ & $\begin{array}{l}\text { Energy restricted } \\
40 \% \text { fat } \\
40 \% \text { carbohydrate }\end{array}$ & 0.0 & 2 \\
\hline Falgarona et al., 2014 & Spain & 81 & 122 & 24 & $\begin{array}{l}\text { Energy restricted } \\
30 \% \text { fat, } \\
52 \% \text { carbohydrate }\end{array}$ & $\begin{array}{l}\text { Energy restricted } \\
40 \% \text { fat, } \\
42 \% \text { carbohydrate }\end{array}$ & $14 \cdot 8$ & 3 \\
\hline Ruth et al., 2013 & USA & 89 & 55 & 12 & $\begin{array}{l}\text { Energy restricted } \\
25 \% \text { fat, } \\
60 \% \text { carbohydrate }\end{array}$ & $\begin{array}{l}\text { Energy restricted } \\
60 \% \text { fat, } \leq 40 \mathrm{~g} / \mathrm{d} \\
\text { carbohydrate }\end{array}$ & $40 \cdot 0$ & 2 \\
\hline Clifton et al., 2004 & Australia & 100 & 70 & 12 & $\begin{array}{l}\text { Energy restricted } \\
12 \% \text { fat, } \\
63 \% \text { carbohydrate }\end{array}$ & $\begin{array}{l}\text { Energy restricted } \\
35 \% \text { fat, } \\
45 \% \text { carbohydrate }\end{array}$ & 11.4 & 2 \\
\hline Saris et al., 2000 & Spain & $50 \cdot 9$ & 372 & 24 & $\begin{array}{l}\text { Reduce fat intake by } 10 \% \\
\text { energy }\end{array}$ & Usual diet & $15 \cdot 1$ & 2 \\
\hline Phillips et al., 2008 & USA & ND & 28 & 6 & $\begin{array}{l}\text { Energy restricted } \\
30 \% \text { fat }\end{array}$ & $\begin{array}{l}\text { Energy restricted } \\
\text { Atkins } \\
\text { low-carbohydrate diet }\end{array}$ & $28 \cdot 6$ & 4 \\
\hline Raatz et al., 2005 & USA & 83 & 29 & 12 & $\begin{array}{l}25 \% \text { fat, } \\
60 \% \text { carbohydrate }\end{array}$ & $\begin{array}{l}40 \% \text { fat, } \\
45 \% \text { carbohydrate }\end{array}$ & 0.0 & 2 \\
\hline $\begin{array}{l}\text { Hernandez et al., } \\
2010\end{array}$ & USA & 69 & 32 & 6 & $\begin{array}{l}\text { Energy restricted } \\
30 \% \text { fat, } \\
55 \% \text { carbohydrate }\end{array}$ & $20 \mathrm{~g} / \mathrm{d}$ carbohydrate diet & 0.0 & 2 \\
\hline Varady et al., 2011 & USA & $29 \cdot 4$ & 20 & 6 & $\begin{array}{l}\text { Energy restricted } \\
25 \% \text { fat }\end{array}$ & $\begin{array}{l}\text { Energy restricted } \\
60 \% \text { fat }\end{array}$ & $15 \cdot 0$ & 4 \\
\hline Haufe et al., 2011 & Germany & 82 & 174 & 24 & $\begin{array}{l}\text { Energy restricted } \leq 20 \% \\
\text { fat }\end{array}$ & $\begin{array}{l}\text { Energy restricted }>30 \% \\
\text { fat }\end{array}$ & 41.4 & 5 \\
\hline
\end{tabular}

* Total number of participants without drop-out.

† JADAD score was graded by modified JADAD score method.

$\ddagger$ Atkins low-carbohydrate diet, a maximum intake of $20 \mathrm{~g}$ carbohydrate/d at the first 2 weeks and then subjects were permitted to increase their intake of carbohydrate to $40-60 \mathrm{~g} / \mathrm{d}$ only if self-testing of urinary ketones continued to indicate ketosis.

$\S$ Danish diet, usual diet of the Danes. 


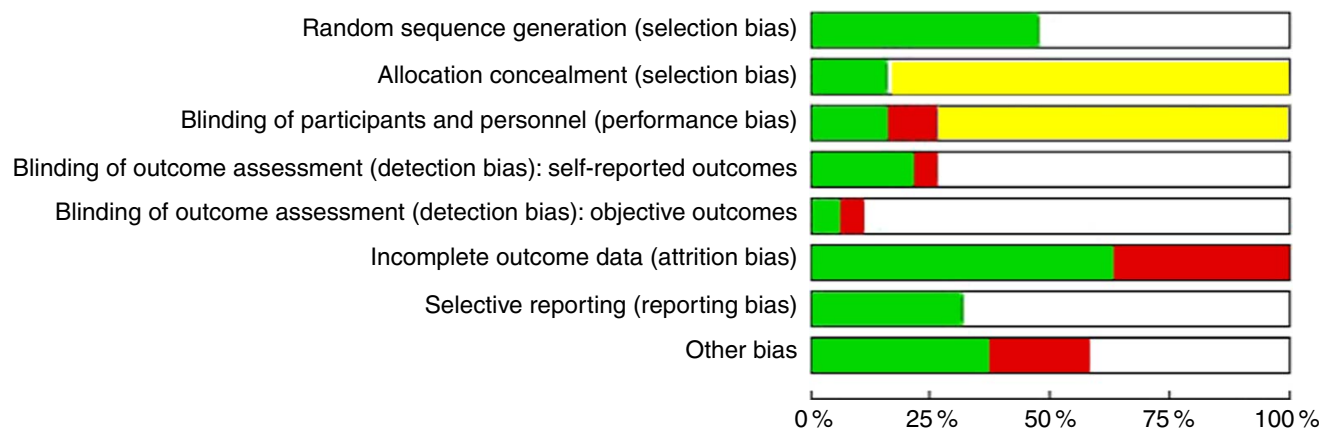

Fig. 2. Summary of risk of bias within the included studies across the six domains: selection bias; performance bias; detection bias; attrition bias; reporting bias; and other bias ${ }^{(22)}$. The proportion of included studies with each judgement: $\square$, low risk of bias; $\square$, unclear risk of bias; $\square$, high risk of bias.

Table 2. Pooled estimates for the effects of low- $v$. high-fat diet on cardiometabolic indicators* (Effect size (ES) of weighted mean difference and $95 \%$ confidence intervals)

\begin{tabular}{lcccrc}
\hline Outcomes & No. of studies & ES & $95 \% \mathrm{Cl}$ & $P$ & $P(\%)$ \\
\hline Weight loss $(\mathrm{kg})$ & 14 & 0.292 & $-0.660,1.244$ & 0.548 & 72.7 \\
Total cholesterol $(\mathrm{mg} / \mathrm{dl})$ & 16 & -7.050 & $-11.296,-2.803$ & 0.001 & 32.8 \\
LDL-cholesterol $(\mathrm{mg} / \mathrm{dl})$ & 18 & -4.406 & $-7.809,-1.003$ & 0.011 & 56.7 \\
HDL-cholesterol (mg/dl) & 18 & -2.568 & $-3.852,-1.285$ & $<0.001$ & 69.4 \\
TAG $(\mathrm{mg} / \mathrm{dl})$ & 19 & 11.679 & $5.903,17.454$ & $<0.001$ & 10.8 \\
Systolic blood pressure $(\mathrm{mmHg})$ & 10 & 1.548 & $-0.374,3.469$ & 0.114 & 0 \\
Diastolic blood pressure $(\mathrm{mmHg})$ & 10 & 2.182 & $0.741,3.624$ & 0.003 & 0 \\
Plasma glucose (mg/dl) & 14 & 0.406 & $-0.614,1.426$ & 0.435 & 30.7 \\
Hs-CRP $(\mu \mathrm{gg} / \mathrm{ml})$ & 7 & 0.184 & $-0.549,0.916$ & 0.623 & 29.6 \\
Adiponectin (total) & 3 & -0.317 & $-0.695,0.061$ & 0.100 & 49.3 \\
Leptin & 5 & -0.047 & $-0.341,0.246$ & 0.752 & 39.2 \\
Plasma insulin & 15 & 0.142 & $-0.035,0.319$ & 0.116 & 46.9
\end{tabular}

* ES $>0$ means low-fat diet increased the indicator when compared with high-fat diets; ES $<0$ means low-fat diet decreased the indicator when compared with high-fat diets; ES $=0$ means low-fat diet makes no difference to the indicator when compared with high-fat diets. $P$ value is $P$ for ES.

\section{Suppressing the conversion from metabolically healthy to metabolically unhealthy obesity}

Epidemiological studies have shown that MHO populations are at a lower risk of some chronic diseases and lower all-cause mortality than metabolically unhealthy obese $(\mathrm{MUO})^{(17,48,49)}$, it is therefore, meaningful to find methods to stop the transition from MHO to MUO. Soriguer et al. ${ }^{(50)}$ have found that after a 6year's follow-up, about $37 \%$ of the $\mathrm{MHO}$ population transformed to MUO, a recent longitudinal study also indicate that $\mathrm{MHO}$ is an intermediate stage to $\mathrm{MUO}^{(51)}$. A prospective study reported that a healthy lifestyle helps to maintain a favourable cardiometabolic profile and thus counterbalance the risk of transition from $\mathrm{MHO}$ to $\mathrm{MUO}^{(20)}$. According to these results, macronutrient composition of the diet, including the amount and the type of dietary fat may play an important role in maintaining metabolic healthy status in people with excess adiposity. However, according to the results of the present meta-analysis, it is unclear what role dietary fat may play in the transition from MHO to MUO.

\section{Dietary fat and body weight}

In this meta-analysis that included participants with excess adiposity and who were metabolically healthy, significant difference between low-fat diets and high-fat diets on weight loss was not found. Besides, no remarkable differences between low-fat diets and high-fat diets were found for either leptin or adiponectin in the present study (Table 2). Both leptin and adiponectin are well known to be inversely correlated with $\mathrm{BW}^{(52,53)}$, leptin represses food intake and increases food expenditure to regulate $\mathrm{BW}^{(54-57)}$. These results are consistent with pooled data from RCT, which showed that low-fat diet have little effect on weight loss during long-term intervention of more than 12 months ${ }^{(58)}$ compared with high-fat diet. However, another meta-analysis concluded RCT and cohort studies found that diets low in total fat were associated with lower relative $\mathrm{BW}^{(59)}$ compared with high-fat diets. These disparate results may be because of the different type of dietary fat and different duration of intervention. As most of the experimental diets were energy restricted, both the low-fat diets and high-fat diets should be effective for weight loss, however, the potential benefits of the high-fat diet may because of the greater satiety. Besides, most of the high-fat diets were also low carbohydrate diets, low carbohydrate diets have been reported to be good for weight loss ${ }^{(60-62)}$. So further studies that aim to compare the effects of low-fat diet with high-fat diet on weight loss should control the percentage of carbohydrate between the two diets.

\section{Dietary fat and CVD}

The proportion of dietary fat in the low-fat diets in this review is consistent with the latest American Dietary Guidelines recommendation on fat intake. In this meta-analysis, high-fat diets 
(a)

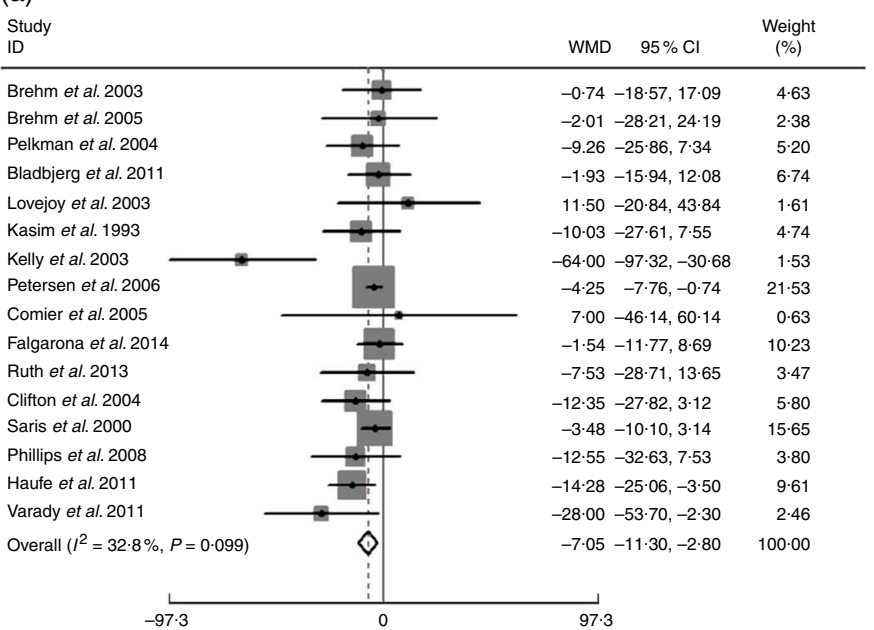

(c)

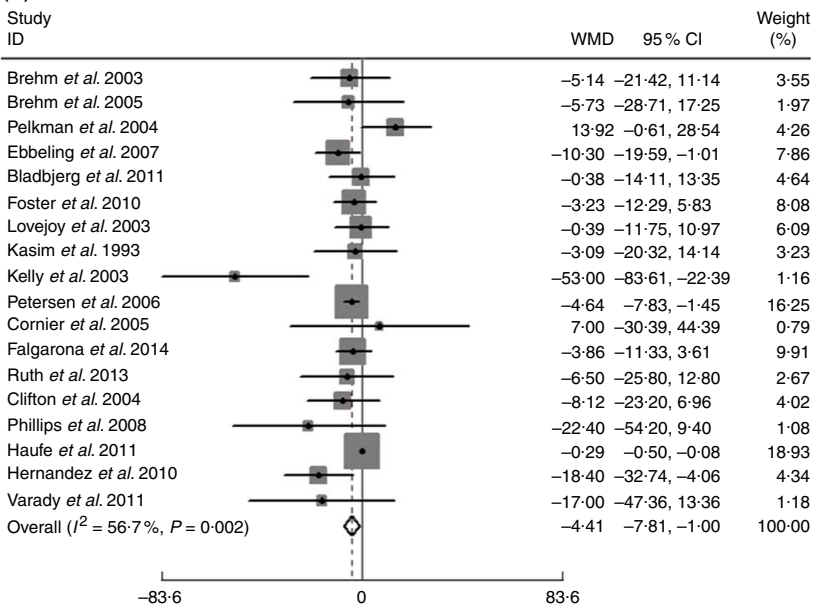

(e)

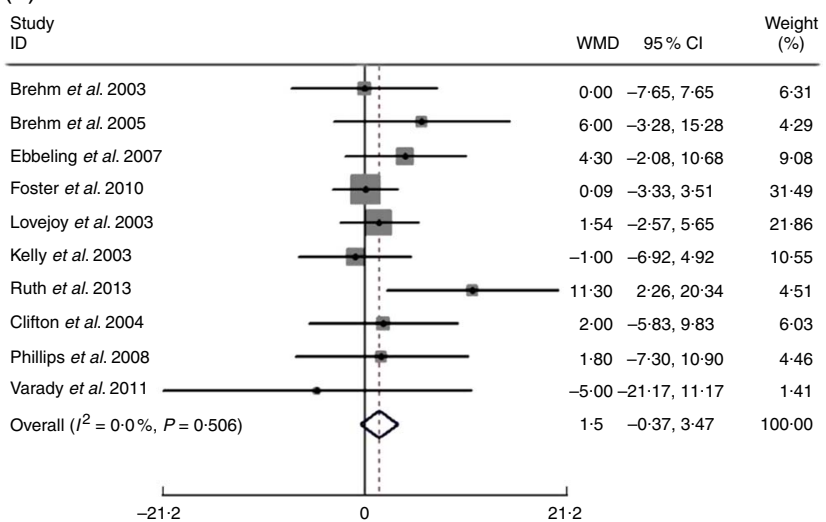

(b)

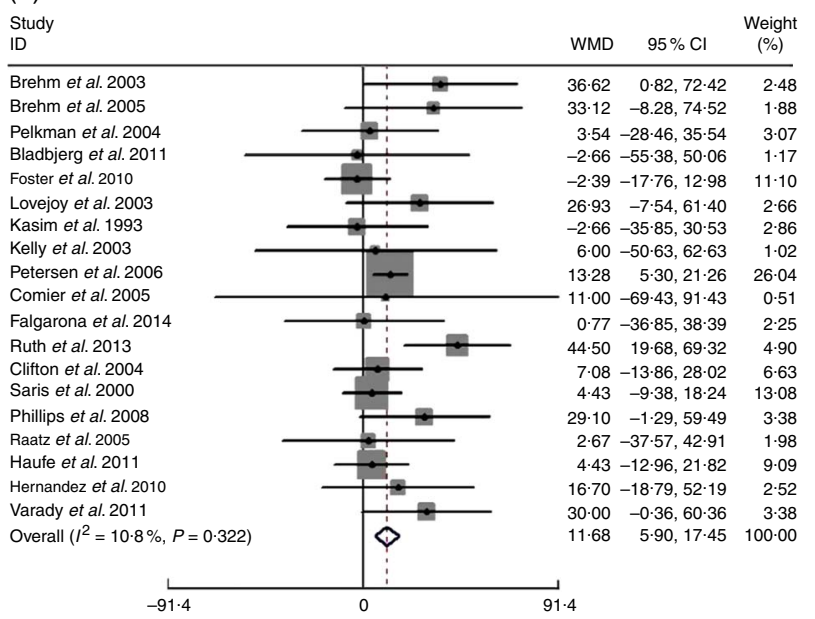

(d)

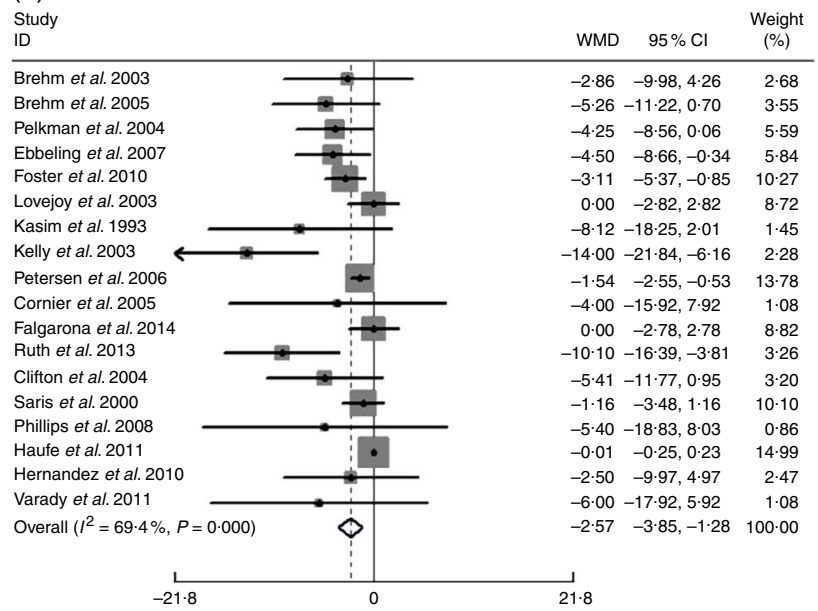

(f)

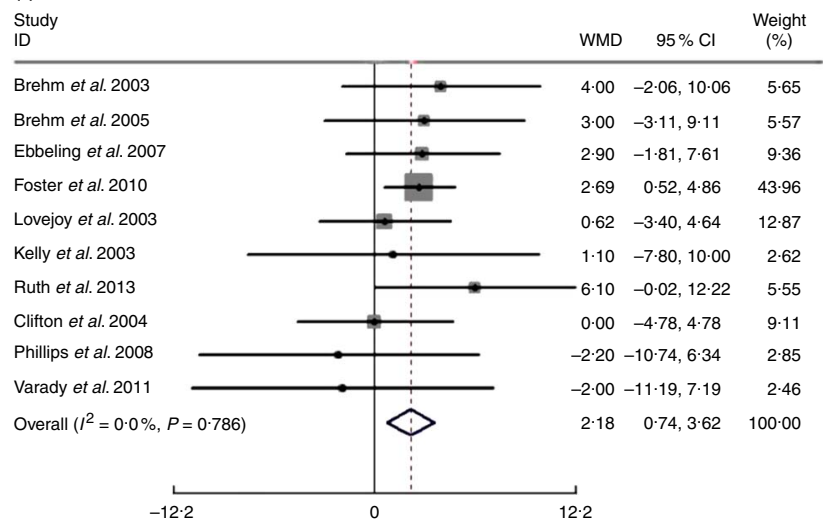

Fig. 3. Effects of low-fat diets compared on high-fat diets on: (a) total cholesterol (TC), (b) TAG (mg/dl), (c) LDL-cholesterol, (d) HDL-cholesterol (mg/dl), (e) systolic blood pressure (SBP) and (f) diastolic blood pressure (DBP) (mmHg). The pooled weighted mean differences (WMD) and $95 \% \mathrm{Cl}$ are shown in the forest plot. WMD was determined with a random-effects model. For TC, TAG, LDL-cholesterol, SBP, DBP, WMD >0 means favours low-fat diet, for HDL-cholesterol, WMD >0 means favours high-fat diet. Weights are from random-effects analysis.

were found to be favourable for TAG $(P<0 \cdot 001)$ and HDLcholesterol $(P<0 \cdot 001)$, and these results are also consistent with the studies including metabolically heterogeneous groups of participants $^{(63-65)}$. In patients with type 2 diabetes, high-fat diet was also associated with lower TAG level and higher HDL- cholesterol level compared with low-fat diet ${ }^{(66)}$. As TAG and HDL-cholesterol levels are important indices for CVD risk, each $10 \mathrm{mg} / \mathrm{dl}(0.26 \mathrm{mmol} / \mathrm{l})$ increase of HDL-cholesterol is associated with a decreased CHD risk of $29 \%{ }^{(67)}$. The present metaanalysis found that high-fat diets can bring an average increase 
Table 3. Subgroup and meta-regression analysis of body weight (BW), plasma insulin and plasma glucose concentrations (Pooled effects and $95 \%$ confidence intervals)

\begin{tabular}{|c|c|c|c|c|c|c|c|c|c|c|c|c|c|c|c|c|c|c|}
\hline \multirow[b]{2}{*}{ Subgroup factors } & \multicolumn{6}{|c|}{ BW } & \multirow[b]{2}{*}{$\begin{array}{l}\text { No. of } \\
\text { trails }\end{array}$} & \multicolumn{6}{|c|}{ Plasma insulin } & \multicolumn{5}{|c|}{ Plasma glucose } \\
\hline & $\begin{array}{l}\text { No. of } \\
\text { trials }\end{array}$ & $\begin{array}{c}\text { Pooled } \\
\text { effect } \\
\text { (mg/dl) }\end{array}$ & $95 \% \mathrm{Cl}$ & $\begin{array}{c}P \\
(\%)\end{array}$ & $P^{\star}$ & $P \dagger$ & & $\begin{array}{l}\text { Pooled effect } \\
\text { (mg/dl) }\end{array}$ & $95 \% \mathrm{Cl}$ & $\begin{array}{l}P \\
(\%)\end{array}$ & $P^{\star}$ & $P \dagger$ & $\begin{array}{l}\text { No. of } \\
\text { trails }\end{array}$ & $\begin{array}{l}\text { Pooled effect } \\
\text { (mg/dl) }\end{array}$ & $95 \% \mathrm{Cl}$ & $\begin{array}{l}P \\
(\%)\end{array}$ & $P^{\star}$ & $P \dagger$ \\
\hline Female (\%) & & & & & & 0.634 & & & & & & 0.944 & & & & & & 0.098 \\
\hline$>80$ & 6 & 0.99 & $-1 \cdot 13,3 \cdot 12$ & $78 \cdot 3$ & 0.360 & & 6 & 0.07 & $-0.3,0.45$ & $66 \cdot 2$ & 0.701 & & 6 & 0.87 & $-1.33,3.07$ & 0 & 0.438 & \\
\hline$\leq 80$ & 5 & 0.13 & $-0.60,0.86$ & 34.4 & 0.732 & & 5 & 0.23 & $-0.06,0.52$ & $44 \cdot 3$ & 0.119 & & 5 & 1.25 & $0.48,2.03$ & 14.4 & 0.002 & \\
\hline Duration (months) & & & & & & 0.983 & & & & & & 0.584 & & & & & & 0.750 \\
\hline$\geq 6$ & 6 & 0.37 & $-1 \cdot 85,2 \cdot 60$ & $82 \cdot 7$ & 0.742 & & 6 & 0.13 & $-0.11,0.37$ & $45 \cdot 8$ & 0.290 & & 6 & 0.13 & $-1.77,2.04$ & $16 \cdot 5$ & 0.893 & \\
\hline $3-6$ & 3 & 0.49 & $-2 \cdot 80,3 \cdot 78$ & $84 \cdot 3$ & 0.770 & & 3 & -0.09 & $-0.84,0.65$ & 73.7 & 0.806 & & 3 & -0.11 & $-2 \cdot 97,2 \cdot 75$ & 0 & 0.940 & \\
\hline$<3$ & 5 & -0.02 & $-0.47,0.43$ & 0 & 0.930 & & 5 & 0.30 & $-0.07,0.66$ & $44 \cdot 8$ & 0.113 & & 5 & 0.53 & $-0.98,2.03$ & $53 \cdot 8$ & 0.493 & \\
\hline Drop-out (\%) & & & & & & 0.097 & & & & & & 0.742 & & & & & & 0.939 \\
\hline$>20$ & 3 & $2 \cdot 51$ & $-0.42,5.43$ & $56 \cdot 2$ & 0.093 & & 5 & 0.19 & $-0.11,0.49$ & $29 \cdot 2$ & 0.211 & & 5 & 0.20 & $-2 \cdot 19,2 \cdot 59$ & 8.4 & 0.872 & \\
\hline$\leq 20$ & 11 & -0.14 & $-1 \cdot 10,0 \cdot 81$ & $70 \cdot 7$ & 0.767 & & 9 & 0.12 & $-0.11,0.35$ & $55 \cdot 4$ & 0.299 & & 9 & 0.41 & $-0.76,1.58$ & $40 \cdot 6$ & 0.490 & \\
\hline $\begin{array}{l}\text { Fat in high-fat diet } \\
(\%)\end{array}$ & & & & & & 0.341 & & & & & & 0.796 & & & & & & 0.147 \\
\hline$\geq 45$ & 3 & 3.98 & $2 \cdot 25,5 \cdot 72$ & 0 & $<0.001$ & & 4 & 0.26 & $-0.26,0.79$ & $51 \cdot 3$ & 0.325 & & 4 & 0.47 & $-4.03,4.96$ & $28 \cdot 7$ & 0.838 & \\
\hline $30-45$ & 7 & -0.55 & $-1.54,0.44$ & $72 \cdot 1$ & 0.279 & & 7 & 0.06 & $-0.17,0.28$ & 57.5 & 0.622 & & 7 & -0.05 & $-1.08,0.98$ & 0 & 0.928 & \\
\hline $\begin{array}{l}\text { Carbohydrate in low- } \\
\text { fat diet (\%) }\end{array}$ & & & & & & 0.599 & & & & & & 0.641 & & & & & & 0.706 \\
\hline$\leq 55$ & 6 & 0.99 & $-1 \cdot 76,3 \cdot 74$ & $86 \cdot 3$ & 0.480 & & 6 & $0 \cdot 16$ & $-0.14,0.46$ & 54 & 0.282 & & 6 & 0.17 & $-2 \cdot 06,2 \cdot 40$ & $61 \cdot 2$ & 0.880 & \\
\hline$>55$ & 5 & -0.05 & $-0.85,0.75$ & $49 \cdot 4$ & 0.904 & & 6 & $0 \cdot 10$ & $-0.24,0.44$ & $59 \cdot 1$ & 0.551 & & 6 & 0.39 & $-0.78,1.57$ & 0 & 0.511 & \\
\hline High-fat diet type & & & & & & 0.043 & & & & & & 0.747 & & & & & & 0.778 \\
\hline Low carbohydrate & 5 & 1.96 & $-0.22,4.14$ & 68 & 0.078 & & 4 & 0.21 & $-0.21,0.64$ & $46 \cdot 8$ & 0.330 & & 4 & 0.79 & $-2 \cdot 75,4 \cdot 33$ & $25 \cdot 3$ & 0.661 & \\
\hline Other type & 9 & -0.48 & $-1.38,0.42$ & 63.3 & 0.298 & & 10 & 0.12 & $-0.08,0.33$ & $50 \cdot 4$ & 0.236 & & 10 & 0.34 & $-0.77,1.45$ & 38.4 & 0.546 & \\
\hline Energy restricted & & & & & & 0.034 & & & & & & 0.362 & & & & & & 0.977 \\
\hline Both restricted & 8 & 0.06 & $-0.57,0.70$ & $25 \cdot 8$ & 0.846 & & 11 & 0.19 & $-0.02,0.40$ & $46 \cdot 7$ & 0.073 & & 11 & 0.07 & $-0.96,1 \cdot 10$ & 0 & 0.892 & \\
\hline Low fat only & 5 & $1 \cdot 31$ & $-1 \cdot 25,3.86$ & 74 & 0.316 & & 2 & 0.12 & $-0.82,1.06$ & $75 \cdot 2$ & 0.799 & & 2 & $2 \cdot 22$ & $-0.32,4.76$ & $27 \cdot 3$ & 0.087 & \\
\hline No & 1 & $-2 \cdot 20$ & $-3 \cdot 26,-1 \cdot 14$ & I & $<0.001$ & & 1 & -0.09 & $-0.36,0.19$ & I & 0.536 & & 1 & -1.80 & $-4.32,0.72$ & I & 0.161 & \\
\hline Continent & & & & & & 0.119 & & & & & & 0.981 & & & & & & 0.467 \\
\hline North America & 10 & $1 \cdot 12$ & $-0.22,2.46$ & $52 \cdot 5$ & 0.102 & & 9 & $0 \cdot 16$ & $-0.17,0.49$ & $48 \cdot 8$ & 0.329 & & 9 & 0.66 & $-0.80,2 \cdot 12$ & $23 \cdot 1$ & 0.373 & \\
\hline Europe & 3 & -0.61 & $-2 \cdot 16,0.93$ & $84 \cdot 6$ & 0.435 & & 4 & 0.12 & $-0.11,0.36$ & 63.5 & 0.300 & & 4 & -0.04 & $-1 \cdot 18,1 \cdot 10$ & 0 & 0.940 & \\
\hline Others & 1 & -1.07 & $-2.47,0.33$ & I & 0.133 & & 1 & $0 \cdot 11$ & $-0.39,0.60$ & I & 0.676 & & 1 & 0.72 & $-3.59,5.03$ & I & 0.743 & \\
\hline JADAD $\ddagger$ score & & & & & & 0.054 & & & & & & 0.537 & & & & & & 0.884 \\
\hline$\geq 4$ & 8 & 1.46 & $-0.14,3.05$ & $72 \cdot 2$ & 0.073 & & 7 & 0.04 & $-0.09,0.17$ & 0 & 0.559 & & 7 & 0.24 & $-1.03,1.51$ & 7.6 & 0.710 & \\
\hline$<4$ & 6 & -0.83 & $-2.22,0.56$ & 73.1 & 0.239 & & 7 & 0.22 & $-0.14,0.58$ & $69 \cdot 7$ & 0.236 & & 7 & 0.40 & $-1 \cdot 20,2 \cdot 01$ & 29.9 & 0.623 & \\
\hline
\end{tabular}

WMD, weighted mean differences.

* $P$ for effect size; it was calculated with a random effect model with weighted mean difference.

T $P$ for univariate meta-regression analysis. WMD was used as the dependent variables and the SE (WMD) as variable name.

¥ JADAD score were graded by modified JADAD score method. 
Table 4. Subgroup and meta-regression analysis of total cholesterol (TC), TAG, LDL-cholesterol and HDL-cholesterol plasma concentrations (Pooled effects and $95 \%$ confidence intervals)

\begin{tabular}{|c|c|c|c|c|c|c|c|c|c|c|c|c|}
\hline \multirow[b]{2}{*}{ Subgroup factors } & \multicolumn{6}{|c|}{ TC } & \multicolumn{6}{|c|}{ TAG } \\
\hline & No. of trials & Pooled effect (mg/dl) & $95 \% \mathrm{Cl}$ & $\begin{array}{c}P \\
(\%)\end{array}$ & $P^{\star}$ & $P \dagger$ & No. of trails & Pooled effect (mg/dl) & $95 \% \mathrm{Cl}$ & $P(\%)$ & $P^{\star}$ & $P+$ \\
\hline \multicolumn{13}{|l|}{ Results for TC and TAG } \\
\hline Female (\%) & & & & & & 0.801 & & & & & & 0.472 \\
\hline$>80$ & 8 & -7.37 & $-12.89,-1.84$ & 0 & 0.009 & & 9 & 14.94 & $2 \cdot 63,27 \cdot 25$ & 30.4 & 0.017 & \\
\hline$\leq 80$ & 5 & -9.28 & $-22 \cdot 20,3 \cdot 63$ & $70 \cdot 7$ & 0.159 & & 7 & $10 \cdot 28$ & $3 \cdot 72,16 \cdot 84$ & 0 & 0.002 & \\
\hline Duration (months) & & & & & & 0.270 & & & & & & 0.284 \\
\hline$\geq 6$ & 8 & -4.69 & $-9.02,-0.37$ & 0 & 0.005 & & 8 & 4.65 & $-3 \cdot 16,12 \cdot 46$ & 0 & 0.243 & \\
\hline $3-6$ & 4 & -6.09 & $-16 \cdot 25,4 \cdot 07$ & 0 & 0.240 & & 5 & 21.53 & $2 \cdot 38,40 \cdot 67$ & $36 \cdot 8$ & 0.028 & \\
\hline$<3$ & 6 & $-12 \cdot 39$ & $-25.85,1.07$ & $76 \cdot 3$ & 0.071 & & 6 & 14.59 & $7.51,21.67$ & 0 & $<0.001$ & \\
\hline Drop-out (\%) & & & & & & 0.179 & & & & & & 0.764 \\
\hline$>20$ & 6 & -8.51 & $-17 \cdot 77,0.75$ & $72 \cdot 3$ & 0.072 & & 5 & $13 \cdot 18$ & $-0.22,26 \cdot 58$ & 2 & 0.054 & \\
\hline$\leq 20$ & 12 & -4.14 & $-7 \cdot 08,-1 \cdot 20$ & $5 \cdot 8$ & 0.006 & & 14 & 11.44 & $4.56,18 \cdot 31$ & 19 & 0.001 & \\
\hline Fat in high-fat diet (\%) & & & & & & 0.052 & & & & & & 0.743 \\
\hline$\geq 45$ & 5 & $-14 \cdot 32$ & $-29.01,0.37$ & $51 \cdot 6$ & 0.056 & & 5 & $35 \cdot 26$ & $20 \cdot 15,50 \cdot 36$ & 0 & $<0.001$ & \\
\hline $30-45$ & 9 & -3.72 & $-6.97,-0.47$ & $11 \cdot 6$ & 0.025 & & 10 & $9 \cdot 88$ & $3 \cdot 88,15 \cdot 88$ & 0 & 0.001 & \\
\hline Carbohydrate in low-fat diet (\%) & & & & & & 0.198 & & & & & & 0.965 \\
\hline$\leq 55$ & 7 & -6.87 & $-11 \cdot 20,-2.54$ & 0 & 0.002 & & 7 & $10 \cdot 77$ & $-0.53,22.08$ & $27 \cdot 5$ & 0.062 & \\
\hline$>55$ & 8 & -3.48 & $-11.05,4.09$ & $59 \cdot 3$ & 0.368 & & 9 & 14.31 & $7 \cdot 70,20 \cdot 93$ & 0 & $<0.001$ & \\
\hline High-fat diet type & & & & & & 0.096 & & & & & & 0.782 \\
\hline Low carbohydrate & 5 & $-15 \cdot 11$ & $-30 \cdot 11,-0 \cdot 10$ & 65.4 & 0.048 & & 6 & $12 \cdot 25$ & $-1.46,25.96$ & 34.5 & 0.080 & \\
\hline Other type & 11 & -4.54 & $-7 \cdot 27,-1 \cdot 82$ & 0 & 0.001 & & 13 & 12.55 & $6 \cdot 87,18 \cdot 22$ & 0.2 & $<0.001$ & \\
\hline Energy restricted & & & & & & 0.603 & & & & & & 0.812 \\
\hline Both restricted & 11 & -10.06 & $-16 \cdot 77,-3.35$ & $52 \cdot 3$ & 0.003 & & 12 & 14.31 & $8 \cdot 10,20.53$ & $2 \cdot 1$ & $<0.001$ & \\
\hline Low fat only & 3 & $-4 \cdot 81$ & $-16 \cdot 11,6 \cdot 48$ & 0 & 0.404 & & 5 & $11 \cdot 19$ & $-5 \cdot 47,27 \cdot 86$ & $35 \cdot 5$ & 0.188 & \\
\hline High-fat only & I & & 1 & l & 1 & & & & & 1 & & 0.560 \\
\hline No & 2 & $-3 \cdot 20$ & $-9 \cdot 18,2 \cdot 79$ & 0 & 0.295 & & 2 & 3.98 & $9 \cdot 38,17.33$ & 0 & 0.853 & \\
\hline Continent & & & & & & 0.454 & & & & & & 0.213 \\
\hline North America & 9 & $-11 \cdot 73$ & $-21.90,-1.56$ & $47 \cdot 2$ & 0.024 & & 12 & $18 \cdot 13$ & $6 \cdot 92,29 \cdot 35$ & $34 \cdot 3$ & 0.002 & \\
\hline Europe & 6 & -4.46 & $-7 \cdot 26,-1 \cdot 66$ & 0 & 0.002 & & 6 & 9.72 & $3.46,15.99$ & 0 & 0.002 & \\
\hline Others & 1 & $-12 \cdot 35$ & $-27 \cdot 82,3.12$ & I & 0.118 & & 1 & 7.08 & $-13.87,28.03$ & I & 0.508 & \\
\hline JADAD scoreł & & & & & & 0.936 & & & & & & 0.521 \\
\hline$\geq 4$ & 7 & -3.43 & $-6.68,-0.17$ & 48.5 & 0.039 & & 8 & 14.14 & $5 \cdot 07,23 \cdot 21$ & 31.8 & 0.002 & \\
\hline$<4$ & 9 & -6.01 & $-14 \cdot 50,2 \cdot 48$ & 60.9 & 0.165 & & 11 & 9.35 & $0.89,17.81$ & 0 & 0.030 & \\
\hline
\end{tabular}


Nesitish Journal of Nutrition

\begin{tabular}{|c|c|c|c|c|c|c|c|c|c|c|c|c|}
\hline \multirow[b]{2}{*}{ Subgroup factors } & \multicolumn{6}{|c|}{ TC } & \multicolumn{6}{|c|}{ TAG } \\
\hline & No. of trials & Pooled effect (mg/dl) & $95 \% \mathrm{Cl}$ & $\begin{array}{c}P \\
(\%)\end{array}$ & $P^{\star}$ & $P \dagger$ & No. of trails & Pooled effect $(\mathrm{mg} / \mathrm{dl})$ & $95 \% \mathrm{Cl}$ & $P(\%)$ & $P^{\star}$ & $P \dagger$ \\
\hline & \multicolumn{5}{|c|}{ LDL-cholesterol } & & \multicolumn{6}{|c|}{ HDL-cholesterol } \\
\hline \multicolumn{13}{|c|}{ Results for LDL-cholesterol and HDL-cholesterol } \\
\hline Female (\%) & & & & & & 0.914 & & & & & & 0.733 \\
\hline$>80$ & 8 & -0.30 & $-0.51,-0.09$ & 0 & 0.006 & & 8 & $-3 \cdot 12$ & $-5.74,-0.49$ & 63.2 & 0.020 & \\
\hline$\leq 80$ & 8 & -5.57 & $-12.07,0.92$ & 67.9 & 0.092 & & 7 & -2.93 & $-4.83,-1.03$ & $60 \cdot 3$ & 0.003 & \\
\hline Duration (months) & & & & & & 0.346 & & & & & & 0.114 \\
\hline$\geq 6$ & 8 & -0.30 & $-0.51,-0.09$ & 0 & 0.005 & & 8 & $-1 \cdot 26$ & $-2 \cdot 60,0.08$ & $54 \cdot 6$ & 0.065 & \\
\hline $3-6$ & 4 & -6.09 & $-16 \cdot 25,4.07$ & 0 & 0.240 & & 4 & $-6 \cdot 63$ & $-10.06,-3.21$ & 0 & $<0.001$ & \\
\hline$<3$ & 6 & -12.39 & $-25.85,1.07$ & $76 \cdot 3$ & 0.071 & & 6 & -4.52 & $-8.08,-0.96$ & $56 \cdot 6$ & 0.013 & \\
\hline Drop-out (\%) & & & & & & 0.724 & & & & & & 0.754 \\
\hline$>20$ & 6 & -8.51 & $-17 \cdot 77,0.75$ & $72 \cdot 3$ & 0.072 & & 5 & -4.46 & $-9.14,0.22$ & $77 \cdot 6$ & 0.062 & \\
\hline$\leq 20$ & 12 & $-4 \cdot 14$ & $-7.08,-1.20$ & $5 \cdot 8$ & 0.006 & & 13 & $-2 \cdot 25$ & $-3.46,-1.05$ & 31.8 & $<0.001$ & \\
\hline Fat in high-fat diet (\%) & & & & & & 0.581 & & & & & & 0.855 \\
\hline$\geq 45$ & 5 & $-14 \cdot 32$ & $-29.01,0.37$ & $51 \cdot 6$ & 0.056 & & 5 & -7.62 & $-11.49,-3.75$ & $27 \cdot 7$ & $<0.001$ & \\
\hline $30-45$ & 9 & -3.72 & $-6.97,-0.47$ & $11 \cdot 6$ & 0.025 & & 9 & -1.62 & $-2.63,-0.60$ & 12 & 0.002 & \\
\hline Carbohydrate in low-fat diet (\%) & & & & & & 0.006 & & & & & & 0.969 \\
\hline$\leq 55$ & 7 & $-6 \cdot 87$ & $-11 \cdot 20,-2.54$ & 0 & 0.002 & & 8 & $-2 \cdot 15$ & $-3.40,-0.90$ & 0 & 0.001 & \\
\hline$>55$ & 8 & -3.48 & $-11.05,4.09$ & $59 \cdot 3$ & 0.368 & & 7 & $-4 \cdot 37$ & $-7.29,-1.45$ & $70 \cdot 5$ & 0.003 & \\
\hline High-fat diet type & & & & & & 0.812 & & & & & & 0.747 \\
\hline Low carbohydrate & 6 & -7.43 & $-16.37,1.52$ & $64 \cdot 8$ & 0.104 & & 6 & -3.78 & $-7.04,-0.52$ & 78.7 & 0.023 & \\
\hline Other type & 12 & -4.56 & $-8.07,-1.05$ & $18 \cdot 3$ & 0.011 & & 12 & $-2 \cdot 22$ & $-3.56,-0.87$ & 33.7 & 0.001 & \\
\hline Energy restriction & & & & & & 0.439 & & & & & & 0.386 \\
\hline Both restricted & 12 & -4.05 & $-8.17,0.07$ & $65 \cdot 7$ & 0.054 & & 12 & -2.48 & $-4.05,-0.91$ & 74 & 0.002 & \\
\hline Low-fat diet only & 5 & -6.50 & -12.69 to -0.31 & 0 & 0.040 & & 5 & -3.46 & $-5 \cdot 38,-1.54$ & 0 & $<0.001$ & \\
\hline High-fat diet only & I & I & I & I & & I & 1 & / & i & & & \\
\hline None & 1 & -0.38 & $-14 \cdot 11,13.35$ & I & 0.005 & & 1 & $-1 \cdot 16$ & $-3.48-1.16$ & I & 0.327 & \\
\hline Continent & & & & & & 0.452 & & & & & & 0.074 \\
\hline North America & 12 & -7.30 & $-14.00,-0.61$ & 52 & 0.033 & & 12 & -4.42 & $-6 \cdot 48,-2 \cdot 36$ & 42 & $<0.001$ & \\
\hline Europe & 5 & -2.07 & $-5.02,0.88$ & 50.9 & 0.169 & & 5 & -0.67 & $-1.68,0.34$ & 58 & 0.195 & \\
\hline Others & 1 & $-8 \cdot 12$ & $-23 \cdot 20,6 \cdot 96$ & 1 & 0.291 & & 1 & -5.41 & $-11.77,0.95$ & l & 0.096 & \\
\hline JADAD score & & & & & & 0.786 & & & & & & 0.237 \\
\hline$\geq 4$ & 9 & -3.43 & $-6.68,-0.17$ & 48.5 & 0.039 & & 9 & -1.67 & $-3.00,-0.33$ & 67 & 0.014 & \\
\hline$<4$ & 9 & $-6 \cdot 01$ & $-14 \cdot 50,2.48$ & 60.9 & 0.165 & & 9 & -4.49 & $-7.33,-1.65$ & 61.7 & 0.002 & \\
\hline
\end{tabular}

* $P$ for effect size; it was calculated with a random effect model with weighted mean difference

$\dagger P$ for meta-regression analysis.

† JADAD score were graded by modified JADAD score method. 
Table 5. $P$ values of publication bias tests

\begin{tabular}{lccr}
\hline Outcomes & $\begin{array}{c}\text { No. of } \\
\text { trials }\end{array}$ & $\begin{array}{c}\text { Begg's test } \\
(P)\end{array}$ & $\begin{array}{c}\text { Egger's test } \\
(P)\end{array}$ \\
\hline Weight loss $(\mathrm{kg})$ & 14 & 0.584 & 0.374 \\
Total cholesterol (mg/dl) & 16 & 0.300 & 0.143 \\
TAG (mg/dl) & 19 & 0.576 & 0.465 \\
LDL-cholesterol (mg/dl) & 18 & 0.820 & 0.010 \\
HDL-cholesterol (mg/dl) & 18 & 0.820 & $<0.001$ \\
Systolic blood pressure $(\mathrm{mmHg})$ & 10 & 0.210 & 0.351 \\
Diastolic blood pressure $(\mathrm{mmHg})$ & 10 & 0.371 & 0.434 \\
Adiponectin (total) & 3 & 0.602 & 0.146 \\
Hs-CRP ( $\mu$ g/ml) & 6 & 0.348 & 0.456 \\
Plasma glucose (mg/dl) & 14 & 0.477 & $<0.001$ \\
Plasma insulin & 14 & 0.784 & 0.773 \\
Leptin & 5 & 1.000 & 0.647 \\
\hline
\end{tabular}

Hs-CRP, high-sensitivity C-reactive protein.

of HDL-cholesterol concentration of $2.57 \mathrm{mg} / \mathrm{dl}(0.066 \mathrm{mmol} / \mathrm{l})$ compared with a low-fat diet which means a relative risk reduction for CVD of $7.45 \%$.

The improvement in TAG after following a high-fat diet may be linked to an increased intake of PUFA which have been demonstrated to be favourable for reducing TAG and VLDLcholesterol as well as increasing HDL-cholesterol. For example, EPA can reduce serum levels of TAG by inhibiting the activity of fat synthetase and reducing fatty acids for synthesising TAG. Besides, $n-6$ PUFA can inhibit the expression of stearyl coenzyme A desaturation enzyme in adipocytes, which is also an important enzyme in the synthesis of TAG.

Interestingly, subgroup analysis by geographical location in the present meta-analysis found greater effect sizes for low-fat diets compared with high-fat diets on serum levels of TC and TAG of trials conducted in North America than in Europe; and for LDL-cholesterol and HDL-cholesterol, those trials conducted in Europe lost statistical significance. Dietary sources of fat often vary between Europe and North America which may further hint towards an effect of fat type as a source of heterogeneity. A limitation of this review is that most of the studies included in this meta-analysis did not analyse the type of fat. Future studies should consider the effect of types of dietary fat on cardiometabolic changes in dietary intervention studies.

\section{Strengths and weaknesses of the article}

The strengths of this meta-analysis and systematic review is the large sample size, with little publication bias evident, which permitted analysis using meta-regression to investigate the potential sources of heterogeneity. The limitations of the present study include: the lack of detailed information on the type of dietary fat which prohibited the analysis of the mechanisms between fat-type and cardiometabolic risk factors; the lack information on blinding within studies which increases the risk of bias and similarly the bias introduced into several studies by the high (>20\%) attrition rate; and the heterogeneity can only be partly explained through the meta-regression performed indicating other unknown factors account for the findings for some parameters.

\section{Conclusion}

This meta-analysis found that people who are overweight/obese but metabolically healthy, exhibit some metabolic changes after dietary fat manipulation. This is mostly characterised by an overall decrease in plasma TC, LDL-cholesterol, HDL-cholesterol and an increase in TAG following low-fat diets compared with high-fat diets. Future studies are needed to focus on the influences of different types of fat. More high-quality RCT for low-fat diet $v$. high-fat diet on metabolically healthy overweight and obese are warranted to inform dietary guidelines.

\section{Acknowledgements}

This study was supported by the National Basic Research Program of China (973 Program: 2015CB553604) and by National Natural Science Foundation of China (NSFC: J20121077).

M. L. and Y. W. performed the database research and data analysis; M. L. wrote the paper; C. E. H., B. Y. and D. L. helped with interpretation of the results and the drafting of the final manuscript.

None of the authors has any conflicts of interest to declare.

\section{Supplementary material}

For supplementary material/s referred to in this article, please visit https://doi.org/10.1017/S0007114517002902

\section{References}

1. World Health Organization (2017) Obesity and overweight. http://www.who.int/mediacentre/factsheets/fs311/en/

2. Hubert HB, Feinleib M, McNamara PM, et al. (1983) Obesity as an independent risk factor for cardiovascular disease: a 26-year follow-up of participants in the Framingham Heart Study. Circulation 67, 968-977.

3. Nguyen NT, Nguyen XMT, Lane J, et al. (2011) Relationship between obesity and diabetes in a US adult population: findings from the national health and nutrition examination survey, 1999-2006. Obes Surg 21, 351-355.

4. Møller H, Mellemgaard A, Lindvig K, et al. (1993) Obesity and cancer risk: a Danish record-linkage study. Eur J Cancer Care 3, 344-350.

5. Sackner-Bernstein J, Kanter D \& Kaul S (2015) Dietary intervention for overweight and obese adults: comparison of lowcarbohydrate and low-fat diets. A meta-analysis. PLOS ONE 10, e0139817.

6. Samaha FF, Lqnal N \& Seshadri P (2003) A low-carbohydrate as compared with a low-fat diet in severe obesity. $N$ Engl J Med 348, 2074-2081.

7. Ma W, Huang T, Zheng Y, et al. (2016) Weight-loss diets, adiponectin, and changes in cardiometabolic risk in the 2-year POUNDS lost trial. J Clin Endocrinol Metab 101, 2415-2422.

8. Mansoor N, Vinknes KJ, Veierød MB, et al. (2016) Effects of low-carbohydrate diets vs low-fat diets on body weight and cardiovascular risk factors: a meta-analysis of randomised controlled trials. Br J Nutr 115, 466-479.

9. Schwingshack L \& Hoffmann G (2013) Comparison of effects of long-term low-fat vs. high-fat diets on blood lipid levels in overweight or obese patients: a systematic review and metaanalysis. J Acad Nutr Diet 113, 1640-1661. 
10. Herrmann W, Reuter W, Schutz C, et al. (1982) The behavior of specific parameters of lipid and lipoprotein metabolism in metabolically healthy and obese subjects. $Z$ Gesamte Inn Med 37, 43-50.

11. Blüher S \& Schwarz P (2014) Metabolically healthy obesity from childhood to adulthood - does weight status alone matter? Metabolism 63, 1084-1092.

12. Sims EAH (2001) Are there persons who are obese, but metabolically healthy? Metabolism 50, 1499-1504.

13. Primeau V, Coderre L, Karelis AD, et al. (2011) Characterizing the profile of obese patients who are metabolically healthy. Int J Obes (Lond) 35, 971-981.

14. Pataky Z, Bobbioni-Harsch E \& Golay A (2010) Open questions about metabolically normal obesity. Int J Obes (Lond) 34, S18-S23.

15. Velho S, Paccaud F, Waeber G, et al. (2010) Metabolically healthy obesity: different prevalences using different criteria. Eur J Clin Nutr 64, 1043-1051.

16. Fangjian G \& Garvey WT (2016) Cardiometabolic disease risk in metabolically healthy and unhealthy obesity: stability of metabolic health status in adults. Obesity 24, 516-525.

17. Das SK, Ma LJ \& Sharma N (2015) Adipose tissue gene expression and metabolic health of obese adults. Int $J$ Obes (Lond) 39, 869-873.

18. Badoud F, Karen PL, Alicia DB, et al. (2014) Serum and adipose tissue amino acid homeostasis in the metabolically healthy obese. J Proteome Res 13, 3455-3466.

19. Phillips CM, Dillon C, Harrington JM, et al. (2013) Defining metabolically healthy obesity: role of dietary and lifestyle factors. PLOS ONE 8, e76188.

20. Schroder H, Ramos R, Baena-Diez JM, et al. (2014) Determinants of the transition from a cardiometabolic normal to abnormal overweight/obese phenotype in a Spanish population. Eur J Nutr 53, 1345-1353.

21. Higgins JP \& Green S (2013) Cochrane handbook of systematic reviews of interventions. Version 5.1.0. Updated March 2011. http://handbook. cochrane.org/ (accessed August 2013).

22. Wildman RP, Muntner P, Reynolds K, et al. (2008) The obese without cardiometabolic risk factor clustering and the normal weight with cardiometabolic risk factor clustering: prevalence and correlates of 2 phenotypes among the US population (NHANES 1999-2004). Arch Intern Med 168, $1617-1624$.

23. Moher D, Liberati A, Tetzlaff J, et al. (2009) Preferred reporting items for systematic reviews and meta-analysis: the PRISMA statement. Ann Intern Med 151, 264-269.

24. Jadad AR, Andre Moore R, Carroll D, et al. (1996) Assessing the quality of reports of randomized clinical trials: is blinding necessary? Control Clin Trials 17, 1-12.

25. Higgins JPT, Altman DG, Gotzsche PC, et al. (2011) The Cochrane Collaboration's tool for assessing risk of bias in randomised trials. BMJ 343, d5928.

26. DerSimonian R \& Laird N (1986) Meta-analysis in clinical trials. Control Clin Trials 7, 177-188.

27. Higgins JP (2003) Measuring inconsistency in meta-analyses. BMJ 327, 557-560.

28. Juanola-Falgarona M, Salas-Salvadó J, Ibarrola-Jurado N, et al. (2014) Effect of the glycemic index of the diet on weight loss, modulation of satiety, inflammation, and other metabolic risk factors: a randomized controlled trial. Am J Clin Nutr 100, $27-35$.

29. Hernandez TL, Sutherland JP, Wolfe P, et al. (2010) Lack of suppression of circulating free fatty acids and hypercholesterolemia during weight loss on a high-fat, low-carbohydrate diet. Am J Clin Nutr 91, 578-585.
30. Pelkman CL, Fishell VK, Maddox DH, et al. (2004) Effects of moderate-fat (from monounsaturated fat) and low-fat weightloss diets on the serum lipid profile in overweight and obese men and women. Am J Clin Nutr 79, 204-212.

31. Foster GD, Wyatt HR, Hill JO, et al. (2010) Weight and metabolic outcomes after 2 years on a low-carbohydrate versus low-fat diet: a randomized trial. Ann Intern Med 3, $147-157$

32. Bladbjerg EM, Larsen TM, Due A, et al. (2011) Effects on markers of inflammation and endothelial cell function of three ad libitum diets differing in type and amount of fat and carbohydrate: a 6-month randomized study in obese individuals. $\mathrm{Br}$ J Nutr 106, 123-129.

33. Phillips SA, Jurva JW, Syed AQ, et al. (2008) Benefit of low-fat over low-carbohydrate diet on endothelial health in obesity. Hypertension 2, 376-382.

34. Petersen M, Taylor MA, Saris WH, et al. (2006) Randomized, multi-center trial of two hypo-energetic diets in obese subjects: high- versus low-fat content. Int J Obes (Lond) $\mathbf{3 0}$, 552-560.

35. Lovejoy JC, Bray GA, Lefevre M, et al. (2003) Consumption of a controlled low-fat diet containing olestra for 9 months improves health risk factors in conjunction with weight loss in obese men: the Ole' Study. Int I Obes Relat Metab Disord 27, 1242-1249.

36. Clifton PM, Noakes M \& Keogh JB (2004) Very low-fat (12\%) and high monounsaturated fat (35\%) diets do not differentially affect abdominal fat loss in overweight, nondiabetic women. J Nutr 134, 1741-1745.

37. Ebbeling CB, Leidig MM, Feldman HA, et al. (2007) Effects of a low-glycemic load vs low-fat diet in obese young adults: a randomized trial. JAMA 297, 2092-2102.

38. Rattz SK, Torkelson CJ, Bruce Redmon J, et al. (2005) Reduced glycemic index and glycemic load diets do not increase the effects of energy restriction on weight loss and insulin sensitivity in obese men and women. $J$ Nutr 135, 2387-2391.

39. Ruth MR, Port AM, Shah M, et al. (2013) Consuming a hypocaloric high fat low carbohydrate diet for 12 weeks lowers C-reactive protein, and raises serum adiponectin and high density lipoprotein-cholesterol in obese subjects. Metabolism 62, 1779-1787.

40. Varady KA, Bhutani S, Klempel MC, et al. (2011) Improvements in vascular health by a low-fat diet, but not a high-fat dietare mediated by changes in adipocyte biology. J Nutr 10, 8 .

41. Cornier MA, Donahoo WT, Pereira R, et al. (2005) Insulin sensitivity determines the effectiveness of dietary macronutrient composition on weight loss in obese women. Obes Res 13, 703-709.

42. Brehm BJ, Seeley RJ, Daniels SR, et al. (2003) A randomized trial comparing a very low carbohydrate diet and a calorierestricted low fat diet on body weight and cardiovascular risk factors in healthy women. J Clin Endocrinol Metab $\mathbf{8 8}$, $1617-1623$

43. Brehm BJ, Spang SE, Lattin BL, et al. (2005) The role of energy expenditure in the differential weight loss in obese women on low-fat and low-carbohydrate diets. J Clin Endocrinol Metab 90, $1475-1482$.

44. Saris WHM, Astrup A, Prentice AM, et al. (2000) Randomized controlled trial of changes in dietary carbohydrate/fat ratio and simple vs complex carbohydrates on body weight and blood lipids: the CARMEN study. The Carbohydrate Ratio Management in European National diets. Int J Obes Relat Metab Disord 24, 1310-1318.

45. Haufe S, Haas V, Utz W, et al. (2013) Long-lasting improvements in liver fat and metabolism despite body weight regain after dietary weight loss. Diabetes Care 36, 3786-3792. 
46. Kasim SE, Martino S, Kim PN, et al. (1993) Dietary and anthropometric determinants of plasma lipoproteins during a long-term low-fat diet in healthy women. Am J Clin Nutr 57, 146-153.

47. Meckling KA, Sullivan CO \& Saari D (2004) Comparison of a low-fat diet to a low-carbohydrate diet on weight loss, body composition, and risk factors for diabetes and cardiovascular disease in free-living, overweight men and women. $J$ Clin Endocrinol Metab 89, 2717-2723.

48. Harmer M \& Stamatakis E (2012) Metabolically healthy obese and risk of all-cause and cardiovascular disease mortality. $J$ Clin Endocrinol Metab 97, 2482-2488.

49. Eckel N, Meidtner K, Uhlmann TK, et al. (2016) Metabolically healthy obesity and cardiovascular events: a systematic review and meta-analysis. Eur J Prev Cardiol 23, 956-966.

50. Soriguer F, Gutierrez-Repiso C, Rubio-Martin E, et al. (2013) Metabolically healthy but obese, a matter of time? Findings from the prospective Pizarra study. J Clin Endocrinol Metab 98, 2318-2325.

51. Appleton SL, Seaborn CJ, Visvanathan R, et al. (2013) Diabetes and cardiovascular disease outcomes in the metabolically healthy obese phenotype: a cohort study. Diabetes Care 36, 2388-2394.

52. Yatagai T, Nagasaka S, Taniguchi A, et al. (2003) Hypoadiponectinemia is associated with visceral fat accumulation and insulin resistance in Japanese men with type 2 diabetes mellitus. Metabolism 52, 1274-1278.

53. Hotta K, Funahashi T, Bodkinet NL, et al. (2001) Circulating concentrations of the adipocyte protein adiponectin are decreased in parallel with reduced insulin sensitivity during the progression to type 2 diabetes in rhesus monkeys. Diabetes 50, 1126-1133.

54. Friedman JM (1999) Leptin and the regulation of body weight. Harvey Lect 95, 107-136.

55. Friedman JM (2002) The function of leptin in nutrition, weight, and physiology. Nutr Rev 60, 1-14.

56. Halaas JL, Gajiwala KS, Maffei M, et al. (1995) Weightreducing effects of the plasma protein encoded by the obese gene. Science 269, 543-546.
57. Pelleymounter MA, Cullen MJ, Baker MB, et al. (1995) Effects of the obese gene product on body weight regulation in obese mice. Science 269, 540-543.

58. Tobias DK, Chen M, Manson JE, et al. (2015) Effect of low-fat diet interventions versus other diet interventions on long-term weight change in adults: a systematic review and metaanalysis. Lancet Diabetes Endocrinol 3, 968-979.

59. Hooper L, Abdelhamid A, Moore HJ, et al. (2012) Effect of reducing total fat intake on body weight: systematic review and meta-analysis of randomised controlled trials and cohort studies. BMJ 345, e7666.

60. Sondike SB \& Copperman N (2003) Effects of a lowcarbohydrate diet on weight loss and cardiovascular risk factor in overweight adolescents. J Pediatr 142, 253-258.

61. Alexandraki I, Palacio C \& Mooradian AD (2015) Relative merits of low-carbohydrate versus low-fat diet in managing obesity. South Med J 108, 401-416.

62. Spieth LE \& Harnish JD (2000) A low-glycemic index diet in the treatment of pediatric obesity. Arch Pediatr Adolesc Med 154, 947-951.

63. Nordmann AJ, Nordmann A, Briel M, et al. (2006) Effects of low-carbohydrate vs low-fat diets on weight loss and cardiovascular risk factors. Arch Intern Med 166, 285-293.

64. McKeown NM, Meigs JB, Liu S, et al. (2004) Carbohydrate nutrition, insulin resistance, and the prevalence of the metabolic syndrome in the Framingham Offspring Cohort. Diabetes Care 27, 538-546.

65. Kodama S, Saito K, Tanaka S, et al. (2009) Influence of fat and carbohydrate proportions on the metabolic profile in patients with type 2 diabetes: a meta-analysis. Diabetes Care 32, 959-965.

66. Briel M, Ferreira-Gonzalez I, You JJ, et al. (2009) Association between change in high density lipoprotein cholesterol and cardiovascular disease morbidity and mortality: systematic review and meta-regression analysis. BMJ 338, b92.

67. Laragh JH (1978) Hypertension Manual. New York: Dun Donnelley Publishing Corp. 